\title{
DESENVOLVIMENTO, DIVERSIDADE E DESIGUALDADE NA PÓS-GRADUAÇÃO EM EDUCAÇÃO DO NORTE E NORDESTE DO BRASIL: UM OLHAR DE GÊNERO
}

\author{
DESARROLLO, DIVERSIDAD Y DESIGUALDAD EN POSTGRADO EN \\ EDUCACIÓN EM BRASIL DE NORTE Y NORDESTE: UNA MIRADA DE GÉNERO
}

\author{
DIAS, Alfrancio Ferreira \\ diasalfrancio@hotmail.com \\ Universidade Federal de Sergipe
}

\begin{abstract}
RESUMO O propósito deste texto é discutir o desenvolvimento, diversidade e as desigualdades de gênero na Pós-graduação em Educação do Norte e Nordeste do Brasil. Através de uma pesquisa quantitativa e documental, buscamos verificar, nos bancos de dados da CAPES, FORPRED-NN, ANPED e PPGED, como a perspectiva de gênero tem sido abordada nos processos de desenvolvimento da Pós-Graduação em Educação. Conclui-se que existe a necessidade de pensarmos a formação do pesquisador em educação pautada no contexto na diversidade cultural para incidir diretamente numa educação para a cidadania.
\end{abstract}

Palavras chave: Desenvolvimento. Diversidade. Educação. Relações de Gênero.

RESUMEN El objetivo de este trabajo es discutir el desarrollo, la diversidad y las desigualdades de género en Postgrado en Educación del Norte y Nordeste. Se buscó a partir de una investigación cuantitativa y documental en bases de datos de CAPES, FORPRED-NN, ANPED, comprobar cómo la perspectiva de género ha sido abordada en los procesos de desarrollo de Postgrado en Educación. Se concluye con una reflexión sobre la necesidad de pensar en la formación de los investigadores en educación basada en el contexto de la diversidad cultural para incidir directamente en una educación para la ciudadanía.

Palabras clave: Desarrollo. Diversidad. Educación. Relaciones de Género.

\section{INTRODUÇÃO}

O objetivo central deste texto é dar visibilidade aos estudos da diversidade e desigualdade de gênero na Pós-Graduação em Educação do Norte e Nordeste do Brasil. Analisamos as particularidades dessas regiões para verificar como a perspectiva de gênero tem sido abordada nos processos de desenvolvimento da pós-graduação em educação, bem como mapeamos as representações das diferenças e desigualdades de gênero. 
No primeiro momento, discutimos algumas concepções sobre os estudos de gênero, refletindo acerca do lugar do gênero nas Políticas de Desenvolvimento da Pós-Graduação em Educação no Norte e Nordeste e, ao mesmo tempo, o conhecimento produzido.

No segundo momento, abordamos as especificidades da Pós-Graduação em Educação das regiões Norte e Nordeste para identificar as diversidades e desigualdades que foram se configurando no processo de implementação e desenvolvimento dos cursos acadêmicos de mestrado e doutorado em educação. Para tanto, utilizamos as informações do Fórum Nacional de Coordenadores de Programas de Pós-Graduação em Educação do Norte e Nordeste (FORPRED-NN), Associação Nacional de Pós-Graduação e Pesquisa em Educação (ANPED), Coordenação de Aperfeiçoamento de Pessoal de Nível Superior (CAPES), bem como através de coleta de dados nos sites dos programas de pós-graduação em educação.

$\mathrm{Na}$ terceira parte, argumentamos a respeito da necessidade de pensar a formação do pesquisador em educação pautada no contexto na diversidade cultural para incidir diretamente numa educação para a cidadania. Acredita-se que a interculturalidade pode promover e oportunizar equidade nas relações interpessoais, na tentativa de diminuir as desigualdades existentes na Pós-Graduação em Educação a partir da inclusão do princípio da diversidade e da alteridade.

\section{A ABORDAGEM DE GÊNERO NA PÓS-GRADUAÇÃO EM EDUCAÇÃO}

A temática do desenvolvimento, diversidade e desigualdade tem ganhado espaço nas discussões das reuniões da ANPED, FORPRED-NN e no Encontro de Pesquisa Educacional do Norte e Nordeste (EPENN), com o objetivo de colaborar no processo de fortalecimento dos programas de pós-graduação em educação, bem como da inserção na pesquisa e produção do conhecimento da temática nas regiões Norte e Nordeste. A realização do EPENN, por exemplo, é uma forma de refletir o "[...] compromisso dos profissionais da área em aprofundar o conhecimento sobre a educação que se realiza nas regiões, buscando, com isso, a melhoria da qualidade do ensino [...] e a formação de novos pesquisadores em educação". (MERCADO; CAVALCANTE, 2007, p. 10). Ante o exposto, entendemos que as reuniões de 
pesquisadores contribuem para a reflexão relativa à profissionalização docente, ao desenvolvimento da educação, às rupturas e contingências e ao processo de socialização.

As abordagens sobre corpo, gênero e sexualidade no campo científico parecem algo que se mistura, apresentando aos pesquisadores e pesquisadoras em Educação a dificuldade de limitar ou pôr fronteiras. A dificuldade reside principalmente quando nos aproximamos das leituras multiculturais, pós-modernas e pós-estruturalistas, pois esses estudos partem da perspectiva de que a linguagem e os processos de significação influenciam a produção do conhecimento.

A Teoria Pós-crítica questiona a centralidade e a conscientização da teoria crítica, que por muito tempo pautou-se na ideia de classe social e na autonomia do indivíduo, focalizando nos aspectos da cultura, da diferença, das representações e dos discursos, na medida em que com as teorias pós-críticas o "[...] mapa do poder é ampliado para incluir os processos de dominação centrados na raça, na etnia, no gênero e na sexualidade" (SILVA, 2010, p. 149).

Assim, as perspectivas multiculturalistas, pós-colonialistas, pós-modernas, pós-estruturalistas, estudos Queer são considerados estudos pós-críticos, que contribuem para pensarmos as questões sobre corpo, gênero e sexualidade no campo da educação, pois problematiza as normatizações e as construções de ideias pré-estabelecidas para pensar uma formação cultural.

Nessa perspectiva, destaca-se neste texto que a adoção do conceito de gênero no âmbito dos estudos de mulheres e feministas tornou o gênero como campo científico. O conceito de gênero é compreendido como um divisor de águas para outra fase distinta da primeira onda do feminismo ${ }^{1}$, e anunciador, de certa forma, da valorização significativa do diferencialismo, da afirmação política das

\footnotetext{
${ }^{1} \mathrm{O}$ Movimento Feminista é entendido aqui como uma posição política que parte do reconhecimento da hierarquia social entre homens e mulheres, sendo considerada historicamente determinada e injusta, e busca eliminá-la. A primeira onda do feminismo teria ocorrido no século XIX e inicio do século XX; refere-se principalmente ao sufrágio feminino, movimentos do século XIX e início do XX preocupados principalmente com o direito da mulher ao voto. A segunda onda(década de 1960-80, a mais famosa) lidava com a desigualdade das leis, bem como as desigualdades culturais, e com o papel da mulher na sociedade. Refere-se às ideias e ações associadas aos movimentos de liberação feminina, que lutavam pela igualdade legal e social para as mulheres. A terceira ondateve inicio na década de 1980 a 1990, e vem até os dias atuais, seria uma continuação - e, segundo alguns autores, uma reação às suas falhas. Cconcentra-se na análise das diferenças, da alteridade, da diversidade e da produção discursiva da subjetividade.
} 
diferenças, dos processos identitários e de igualdades; ou seja, o conceito chama a atenção para a diversidade ou as diferenças dentro da diferença (DIAS, 2014a). Essa argumentação contribui para pensarmos no processo da introdução das políticas públicas de equidade de gênero como uma das possibilidades para o avanço da cidadania e a diminuição das desigualdades sociais, refletindo sobre o papel da formação do pesquisador em educação nesse contexto de constantes mudanças.

Se, na sociedade, o conceito de gênero como construção social foi entendido através de um processo lento, influenciado fortemente pelos debates feministas, no contexto educacional, passou a ser usado recentemente como um dos elementos para entender as novas conjunturas do trabalho docente. Alguns/mas pesquisadores/as têm se dedicado a expor a fragilidade das pesquisas relativas à relação gênero-educação, conforme exposto no trabalho de Rosemberg e Pinto (1985), e mais profundamente discutido por Teixeira (2009) e Louro (2010).

Em conformidade com essa linha de reflexão, algumas questões centrais das práticas educativas - como a produção das diferenças e das desigualdades sexuais de gênero, bem como as articulações com os outros marcadores sociais (raça, etnia, classe) - estão no bojo do debate acadêmico. A instituição escolar é um espaço privilegiado de socialização, nela recebe especial atenção o modo como os sujeitos, em relações sociais atravessadas por diferentes discursos, símbolos, representações e práticas, vão construindo suas identificações, (re)construindo seus lugares sociais, suas disposições, suas formas de ser e estar no mundo. Neste sentido, a pós-graduação em educação deve propiciar a formação de pesquisadores para desenvolverem pesquisas e estudos sobre como as temáticas de gênero, corpo e sexualidades estão sendo trabalhadas ou até mesmo qual o atual panorama da diversidade e da desigualdade no campo da educação. (LOURO, 2010).

É interessante marcar o início desse processo com as contribuições de Beauvoir acerca de gênero. A autora questiona o determinismo biológico (nascer mulher), a fim de refletir quanto a uma concepção social de gênero (tornar-se mulher). Ela lança sua crítica sobre os aspectos culturais do patriarcado, visto que os determinantes sociais, não os biológicos, eram os que deveriam posicionar homens e mulheres na sociedade (BEAUVOIR, 1970). Entretanto, no decorrer de sua obra, mostra como, culturalmente, o masculino é um exemplo de positividade 
(modelo a ser seguido), enquanto as mulheres representam a imagem do "outro". O "outro", nesse caso, é visto como o diferente, com características secundárias, de segundo plano, ou seja, "o segundo sexo". A autora defende que essa relação está ligada às ideias patriarcais que definiam as relações de gênero com um enraizamento nos aspectos biológicos. As distinções entre masculino e feminino são fruto do que a sociedade impõe como papéis para homens e mulheres. A análise traz para sociedade uma nova maneira de ver as mulheres e o papel que estas poderiam ter e desenvolver na sociedade - ou seja, a "[...] passagem do estado natural para a cultural" (BEAUVOIR, 1970, p. 11).

Com relação a esse aspecto, podemos citar também as argumentações de Millett, visto que foi uma das estudiosas que marcaram esse novo momento. Para a autora, as militantes feministas participantes do mundo acadêmico interiorizaram em universidades e escolas questões que mobilizaram estudiosas, docentes e pesquisadoras, na criação de uma nova vertente teórica sobre os "estudos da mulher". (MILLETT, 1970).

A relação entre masculino e feminino não pode ser representada numa economia significante em que o masculino constitua o círculo fechado do significante e do significado. Beauvoir prefigurou essa possibilidade ao argumentar que os homens não poderiam resolver a questão das mulheres porque, neste caso, estariam agindo como juízes e como partes interessadas. A construção discursiva do corpo e a sua separação do estado de liberdade não conseguem marcar no eixo do gênero a própria distinção corpo/mente que deveria esclarecer a persistência da assimetria dos gêneros. Para ela, o corpo feminino é marcado no interior do discurso masculinista; enquanto o corpo masculino, em sua fusão com 0 universal, permanece não marcado. (BEAUVOIR, 1970).

A "[...] construção do gênero também se faz por meio de sua desconstrução". (LAURETIS, 1994, p. 235). Então, ao aceitar que a construção do gênero é histórica e se faz incessantemente, entende-se que as relações entre homens e mulheres, os discursos e as representações dessas relações estão em constante mudança. (LAURETIS, 1994). Isso supõe que as identidades de gênero estão continuadamente se transformando, por isso é indispensável admitir que até mesmo as teorias e as práticas feministas estão construindo o gênero. A ideia de Lauretis (1994) sobre gênero, como produto e processo de representação da sociedade, é 
bastante significativa, visto que abrange os significados construídos da identidade do "outro" em determinado lugar, bem como o papel atribuído por cada pessoa (homem ou mulher) nas relações que são construídas nesse lugar.

Butler vai além dessa discussão, quando questiona a construção do gênero, pois, para ela, cotidianamente há uma tendência a considerar natural o que é o masculino e o feminino. A representação da figura masculina e da feminina, no entanto, não se restringe absolutamente à condição "do ser do macho e do ser fêmea", mas sim ultrapassa bastante esses limites biológicos. (BUTLER, 2010). Trata-se, com efeito, de construções e desconstruções sociais e culturais de grande complexidade, modeladas por regras e códigos simbólicos da sociedade. Dessa forma, coloca-se em pauta a indicação dos limites dessas interpretações, principalmente quando questiona a Biologia (BUTLER, 2010). No entender da autora, as identidades dos indivíduos já são potencialmente contestadas pela distinção que abre espaço ao gênero como interpretação múltipla do sexo; em outras palavras:

[...] a ideia de que o gênero é construído sugere certo determinismo de significados de gênero, descritos em corpos anatomicamente diferenciados, sendo estes corpos compreendidos como recipientes passivos de uma lei cultural inexorável. (BUTLER, 2010, p. 26).

Embora o trabalho de Butler seja deveras eficiente para entender os mais variados "problemas de gênero", principalmente das ideias e questões feministas referentes à insubordinação da identidade, ela extrapola a discussão sobre gênero. Butler questiona o construto sexo-gênero, ou seja, as formas de construção do sexo e do gênero no processo histórico-cultural da sociedade, a fim de chegar à conclusão de que é necessário passar por um processo de "desconstrução" do gênero ${ }^{2}$, dando ênfase à "performance" do corpo ${ }^{3}$. (BUTLER, 2010).

2 O termo "desconstrução" é utilizado para questionar os significados atribuídos aos papéis de homens e mulheres nas relações construídas socialmente e naturalizados como masculino e feminino (a condição do ser do macho e do ser fêmea). Os significados do gênero devem ultrapassar bastante esses limites biológicos, para que possamos incluir as identidades de gênero que não se encaixam nessas normatizações ou mesmo as que se encontram em fronteira (travestis, transexuais e intersex).

${ }^{3}$ Judith Butler desconstrói a ideia determinista de gênero como um construto social, pois isso retorna a afirmarmos que sexo e gênero são vistos como uma única coisa numa ordem biológica incontestável. Nesse sentido, a performance das identidades sexuais e de gênero dos indivíduos que "fogem" do normal (homem/mulher, masculino/feminino) são potencialmente contestadas pela 
Nessa linha de reflexão, defende-se aqui que o gênero como uma categoria de análise histórico-cultural (LAURETIS, 1994), estabelecida pela experiência (THOMPSON, 1981) que pode ser influenciada pelo processo de representação. Joan Scott também contribui para a fundamentação dessa perspectiva, visto que considera o gênero como "[...] um elemento constitutivo das relações sociais fundadas sobre as diferenças percebidas entre os sexos" (SCOTT, 1995, p. 42). Assim, o gênero é visto como uma categoria explicativa para a análise históricocultural, pelo fato de que sua elaboração situa-se no conjunto das relações sociais, nas construções dessas relações e nos processos culturais vivenciados pela sociedade.

No contexto das pesquisas brasileiras, pode ser destacado o trabalho de Louro (2010), obra pós-estruturalista sobre a perspectiva do gênero como uma categoria de análise constituída a partir dos estudos do movimento feminista. A autora propõe um "pensamento plural" que ligue a concepção de gênero às representações sociais e não mais às argumentações biológicas. A discussão sobre o gênero, nesse caso, passa a ser pensada a partir da caracterização do que é masculino e do que é feminino na sociedade, das formas como os sujeitos compreendem e representam suas identificações nas práticas sociais, que assumem novos contornos no processo histórico. Assim, o conceito de gênero "[...] passa a ser usado, então, como um forte apelo relacional - já que é no âmbito das relações sociais que se constroem os gêneros" (LOURO, 2010, p. 22). Nessa perspectiva, ao rever as características masculinas e femininas no contexto social, como propõe a autora, é preciso refletir acerca das relações sociais construídas por homens e mulheres, e não somente priorizar as mulheres em suas análises. O entendimento de "apelo relacional" está centrado na contextualização (no que se afirma ou supõe) sobre o gênero.

Cruz e França salientam que pensar a definição de gênero como uma construção social constitui um "princípio organizador" que influencia as experiências dos sujeitos, as formas de analisar e refletir quanto aos fenômenos, a fim de integrar (micro/macro, estrutura/sujeito) ao processo das relações sociais e, principalmente, na análise do desenvolvimento social. Desse modo, os sujeitos constroem suas subjetividades a partir da participação ampla nas relações sociais, num processo de performatividade do gênero a partir de masculinidades e feminilidades fluídas. 
"internalização/externalização" de ações construídas e compreendidas pelo eu ou pelos outros, dentro do processo de socialização. (CRUZ; FRANÇA, 2011).

Ao refletir a respeito dessas principais perspectivas teóricas sobre a categoria de análise "gênero", percebemos a importância do desenvolvimento da temática, bem como de outras temáticas que se aproximam desse debate. Dentre elas se destacam as discussões sobre o corpo, sexualidades, masculinidades, feminilidades, transexualidades, raça e classe nas pesquisas e estudos nas pósgraduações em educação.

Assim, ao pensarmos sobre o lugar dessas temáticas nas Políticas de Desenvolvimento da Pós-Graduação em Educação no Norte e Nordeste, ao mesmo tempo, estaremos contribuindo para a produção do conhecimento sobre gênero, bem como demarcar sua importância para a formação do/a pesquisador/a em educação.

\section{DIVERSIDADES E DESIGUALDADES NA PÓS-GRADUAÇÃO EM EDUCAÇÃO}

As temáticas relativas a multiculturalismo, processos identitários, diversidades e desigualdades estão ganhando espaço nas pesquisas da pós-graduação em educação em todo o Brasil, com rupturas, contingências e deslocamentos que circulam e fazem se entrelaçar ideias e produções de diferentes pesquisadores/as do Norte e Nordeste, bem como em outras fronteiras. Nessa perspectiva, o multiculturalismo é pensado aqui como o estudo dos processos culturais e seus efeitos significativos que se configuram nas relações sociais, decorrentes das diferenças relativas ao gênero, sexualidades, etnia, raça religião, classe, geração que diferenciam indivíduos e os grupos sociais (CANDAU, 2010).

No campo da educação, o multiculturalismo, a cultura e a interculturalidade contribuem para refletirmos quanto aos posicionamentos dos agentes escolares $\mathrm{e}$ das instituições de ensino, bem assim sobre as representações da diversidade e como agirmos com as diferenças, visto que as práticas formativas devem levar em consideração as questões culturais da sociedade em que se inserem. A perspectiva da interculturalidade pode promover uma educação para o "[...] reconhecimento do 'outro', para o diálogo entre os diferentes grupos sociais e culturais" (CANDAU, 2010, p. 23). Para a autora, ao reconhecer o outro, os agentes escolares podem 
desenvolver um processo de "negociação", no qual as relações de poder entre os indivíduos e os diversos grupos sociais favoreçam a construção de novas relações sociais em que as diferenças são reconhecidas e incluídas. Assim, a interculturalidade é um processo dinâmico que se "[...] constrói entre pessoas, conhecimentos, saberes e práticas culturalmente diferentes, buscando desenvolver um novo sentido entre eles na sua diferença" (WALSH, 2001, p. 10). O fruto dessas relações seria as estratégias de interação social dos agentes e a sociedade para a construção de uma nova realidade, mediada pela comunicação e pelas parcerias, ou seja, relação intrínseca entre o "eu" e os "outros".

O mesmo acontece na pós-graduação, visto que no processo de interações e representações sociais dos agentes, relações de parcerias são construídas, testadas e reformuladas a partir das inter-relações humanas. As identidades dos/as docentes são construídas nos moldes da "continuidade" e "ruptura" das transações objetivas/subjetivas e externas/internas, ou seja, as identidades profissionais estão num processo de mudança a partir do movimento de "desestruturação/ reestruturação" (DUBAR, 2005). Interessa-nos saber, através de um mapeamento da pós-graduação em educação das regiões Norte e Nordeste, como as diversidades e as diferenças foram se configurando no processo de implementação e desenvolvimento dos cursos de mestrado e doutorado acadêmicos e mestrados profissionais em educação.

Para tanto, realizamos uma pesquisa quantitativa, na qual utilizamos as variáveis objetivas: a) números de mestrados, mestrados/doutorados acadêmicos e mestrados profissionais das regiões Nordeste e Norte; b) número de núcleos de pesquisa e estudos de gênero das regiões Nordeste e Norte; e c) número de dissertações e teses com abordagem de gênero na UFS. Como estratégia de coleta de dados, realizamos um levantamento de informações dos cursos recomendados/reconhecidos pela CAPES, bem como do Fórum Nacional de Coordenadores de Programas de Pós-Graduação em Educação do Norte e Nordeste (FORPRED-NN), Associação Nacional de Pós-Graduação e Pesquisa em Educação (ANPED), acrescentamos, ainda, a coleta de dados realizada nos sites dos Programas de Pós-Graduações em Educação do Norte e Nordeste. Nos quadros 01 e 02 apresentamos um panorama da oferta dos cursos de pós- 
graduação em educação, por região, estado e instituição de ensino que oferecem cursos de Mestrado, Mestrado Profissional e Mestrado/Doutorado.

\begin{tabular}{|c|c|c|c|c|c|}
\hline ESTADO & IES & $\mathbf{M}$ & MP & M/D & TOTAL \\
\hline Alagoas & Universidade Federal de Alagoas (UFAL) & & & 1 & 1 \\
\hline \multirow{6}{*}{ Bahia } & Universidade Federal da Bahia (UFBA) & & 1 & 1 & 2 \\
\hline & Universidade Federal do Recôncavo da Bahia (UFRB) & 1 & & & 1 \\
\hline & Universidade Estadual de Feira de Santana (UEFS) & 1 & & & 1 \\
\hline & Universidade Estadual do Sudoeste da Bahia (UESB) & 1 & & & 1 \\
\hline & Universidade Estadual de Santa Cruz (UESC) & 1 & & & 1 \\
\hline & Universidade do Estado da Bahia (UNEB) & & 3 & 1 & 4 \\
\hline \multirow{2}{*}{ Ceará } & Universidade Federal do Ceará (UFC) & & & 1 & 1 \\
\hline & Universidade Estadual do Ceará (UECE) & 1 & & 1 & 2 \\
\hline Maranhão & Universidade Federal do Maranhão (UFMA) & 1 & & & 1 \\
\hline \multirow{2}{*}{ Paraíba } & Universidade Federal da Paraíba (UFPB) & & 1 & 1 & 2 \\
\hline & Universidade Estadual da Paraíba (UEPB) & & 1 & & 1 \\
\hline \multirow{3}{*}{ Pernambuco } & Universidade Federal de Pernambuco (UFPE) & 1 & & 1 & 2 \\
\hline & Universidade Federal Rural de Pernambuco (ÚFPE) & 1 & 1 & & 2 \\
\hline & Fundação Universidade de Pernambuco (FESP/UPE) & & 1 & & 1 \\
\hline Piauí & Universidade Federal do Piauí (UFPI) & & & 1 & 1 \\
\hline \multirow{3}{*}{$\begin{array}{l}\text { Rio Grande } \\
\text { do Norte }\end{array}$} & Universidade Federal do Rio Grande do Norte (UFRN) & & & 1 & 1 \\
\hline & Universidade Estadual do Rio Grande do Norte (UERN) & 1 & & & 1 \\
\hline & Instituto Federal do Rio Grande do Norte (IFRN) & 1 & & & 1 \\
\hline \multirow{2}{*}{ Sergipe } & Universidade Federal de Sergipe (UFS) & & & 1 & 1 \\
\hline & Universidade Tiradentes (UNIT) & & & 1 & 1 \\
\hline Total & & 10 & 08 & 11 & 29 \\
\hline
\end{tabular}

Fonte: CAPES 2014. (M - Mestrado, MP - Mestrado Profissional ; M/D - Mestrado e doutorado )

Quadro 2: Oferta de Cursos de Pós-graduação em Educação no Norte

\begin{tabular}{|l|l|c|c|c|c|}
\hline \multicolumn{1}{|c|}{ ESTADO } & \multicolumn{1}{|c|}{ IES } & M & MP & M/D & TOTAL \\
\hline Acre & Universidade Federal do Acre (UFAC) & 1 & & & 1 \\
\hline Amazonas & Universidade Federal do Amazonas (UFAM) & & & 1 & 1 \\
\hline \multirow{3}{*}{ Pará } & Universidade Federal do Pará (UFPA) & 1 & & 1 & 1 \\
\cline { 2 - 6 } & Universidade Federal do Oeste do Pará (UFOPA) & 1 & & & 1 \\
\cline { 2 - 6 } & Universidade do Estado do Pará (UEPA) & 1 & & & 1 \\
\hline Rondônia & Universidade Federal de Rondônia (UNIR) & 1 & 1 & & 2 \\
\hline Roraima & Universidade Estadual de Roraima (UERR) & 1 & 1 & & 2 \\
\hline Tocantins & Universidade Federal de Tocantins (UFT) & 1 & & & 1 \\
\hline Total & & $\mathbf{7}$ & $\mathbf{2}$ & $\mathbf{2}$ & $\mathbf{1 1}$ \\
\hline
\end{tabular}

Fonte: CAPES 2014. (M - Mestrado, MP - Mestrado Profissional; M/D - Mestrado e doutorado).

Ao observarmos as informações coletadas, é possível verificar a diversidade e desigualdade no que se refere à oferta de cursos de pós-graduação em relação ao Nordeste e Norte. No que tange às duas regiões, o Nordeste possui 29 cursos e o Norte 11, distribuídos por universidades públicas federais, estaduais, institutos federais e uma universidade privada localizada no estado de Sergipe. Desses 40 
programas de pós-graduação em educação, apenas 13 ofertam os cursos de mestrado e doutorado acadêmicos, 11 situados na região Nordeste: UFAL, UFBA, UNEB, UFPI, UFC, UECE, UFPE, UFRN, UFPB UFS e UNIT; dois situados na região Norte: UFAM e UFPA.

Os dados inferem a necessidade de ampliação do desenvolvimento da interiorização da pós-graduação em educação, principalmente, na região Norte, visto que é a maior do país em território e a menor em oferta de cursos de pós-graduação em educação. Também, faz-se necessário ter uma política de formação dos profissionais vinculados às instituições de ensino superior, para que esses, ao retornarem as suas instituições de origem, possam desenvolver grupos de pesquisas e elaborarem propostas de novos cursos a fim de diminuir as desigualdades em relação às outras regiões. Dos 126 mestrados acadêmicos, 66 doutorados e 33 mestrados profissionais reconhecidos pela CAPES, apenas 17 cursos de mestrado acadêmico, 13 de doutorado e 10 mestrados profissionais, respectivamente, estão localizados nas regiões Norte e Nordeste.

Acreditamos que o início da inclusão da perspectiva de gênero na educação superior e nos programas de pós-graduação em educação no Norte e Nordeste deuse a partir da criação da Rede Feminista Norte e Nordeste de Estudos e Pesquisa sobre Mulher e Relações de Gênero (REDOR), em 1992. A REDOR surgiu a partir de encontros de pesquisadoras feministas para articular e fortalecer os núcleos e grupos de pesquisas que desenvolviam estudos sobre mulheres e relações de gêneros nas universidades das regiões Norte e Nordeste. Com a socialização dessas pesquisas, através da realização de seus 18 encontros em diversas universidades das duas regiões, com conferências, mesas-redondas e vários grupos de trabalho, a produção do conhecimento vem se fortalecendo.

A manutenção da REDOR e dos núcleos de pesquisa tem sido um desafio para os/as pesquisadores/as objetivando a dar visibilidade às pesquisas desenvolvidas sobre gênero, à formação de novos/as pesquisadores/as nas instituições de ensino superior e à inserção de pesquisadores/as nos cursos de pósgraduação em nível de mestrado e doutorado nas regiões Norte e Nordeste.

Quadro 3: Núcleos de Estudos e Pesquisa vinculados a REDOR do Nordeste

\begin{tabular}{|c|c|c|c} 
ESTADO & IES & NÚCLEOS DE PESQUISA & № DE
\end{tabular}




\begin{tabular}{|c|c|c|c|}
\hline & & & $\begin{array}{l}\text { PESQUISADO } \\
\text { RES/AS }\end{array}$ \\
\hline Alagoas & UFAL & Núcleo Temático Mulher e Cidadania (NTMC) & 11 \\
\hline \multirow{3}{*}{ Bahia } & UFBA & $\begin{array}{l}\text { Núcleo de Estudos Interdisciplinares sobre a Mulher } \\
\text { (NEIM) }\end{array}$ & 21 \\
\hline & UFBA & $\begin{array}{l}\text { Núcleo de Estudos da Cultura e da Literatura Feminina } \\
\text { (NECLIF) }\end{array}$ & 06 \\
\hline & UEFS & $\begin{array}{l}\text { Núcleo de Estudos Interdisciplinares sobre a Mulher e } \\
\text { Relações de Gênero (MULLIERIBUS) }\end{array}$ & 16 \\
\hline Ceará & UFC & $\begin{array}{l}\text { Núcleo de Estudos e Pesquisas sobre Gênero, Idade e } \\
\text { Família (NEGIF) }\end{array}$ & 23 \\
\hline Maranhão & UFMA & $\begin{array}{l}\text { Núcleo Interdisciplinar de Estudos e Pesquisas Mulher, } \\
\text { Cidadania e Relações de Gênero (NIEPEM) }\end{array}$ & - \\
\hline \multirow{3}{*}{ Paraíba } & UFPB & $\begin{array}{l}\text { Núcleo Interdisciplinar de Pesquisa e Ação sobre Mulher } \\
\text { e Relações de Sexo e Gênero (NIPAM) }\end{array}$ & 13 \\
\hline & UFCG & Núcleo de Estudos da Mulher Sertaneja (NEMJ) & - \\
\hline & UFPB & $\begin{array}{l}\text { Núcleo de Estudos e Pesquisas sobre Gênero e Direito } \\
\text { (NEPGD) }\end{array}$ & 5 \\
\hline \multirow{5}{*}{ Pernambuco } & UFPE & Família, Gênero e Sexualidade (FAGES) & 22 \\
\hline & UFRPE & Núcleo de Estudos e Pesquisas da Mulher & - \\
\hline & UFPE & $\begin{array}{l}\text { Núcleo de Pesquisas em Gênero e Masculinidades } \\
\text { (GEMA) }\end{array}$ & 25 \\
\hline & UFRPE & Núcleo de Pesquisa - Ação Mulher e Ciência (NPAMC) & 13 \\
\hline & UFRPE & Intitulo Papai & 10 \\
\hline Piauí & UFPI & $\begin{array}{l}\text { Núcleo de Estudos e Pesquisas sobre Mulher e } \\
\text { Relações de Gênero (NEPEM) }\end{array}$ & 61 \\
\hline \multirow{2}{*}{$\begin{array}{l}\text { Rio Grande } \\
\text { do Norte }\end{array}$} & UFRN & $\begin{array}{l}\text { Núcleo Nísia Floresta de Estudos e Pesquisa na Área } \\
\text { da Mulher e Relações Sociais de Gênero (NEPAM) }\end{array}$ & 10 \\
\hline & UERN & $\begin{array}{l}\text { Núcleo de Estudos sobre a Mulher Simone de Beauvoir } \\
\text { (NEM) }\end{array}$ & - \\
\hline Sergipe & UFS & $\begin{array}{l}\text { Núcleo de Estudos e Pesquisas Interdisciplinares sobre } \\
\text { a Mulher e Relações de Gênero (NEPIMG) }\end{array}$ & 10 \\
\hline Total & 12 & & 246 \\
\hline
\end{tabular}

Fonte: UFRPE, 2014.

Quadro 4: Núcleos de Estudos e Pesquisa vinculados a REDOR do Norte

\begin{tabular}{|l|c|l|c|}
\hline \multicolumn{1}{|c|}{ ESTADO } & IES & \multicolumn{1}{|c|}{ NÚCLEO DE PESQUISA } & $\begin{array}{c}\text { No DE } \\
\text { PESQUISADORES/AS }\end{array}$ \\
\hline Acre & UFAC & Núcleo de Estudos de Gênero na Amazônia & - \\
\hline Amazonas & UFAM & $\begin{array}{l}\text { Núcleo de Estudos e Pesquisas } \\
\text { Interdisciplinares de Relações de Gênero no } \\
\text { Amazonas -(NEIREGAM) }\end{array}$ & - \\
\hline Rondônia & UNIR & Núcleo de Estudo e Pesquisa da Mulher & - \\
\hline Tocantins & UFT & $\begin{array}{l}\text { Núcleo de Estudos, Pesquisa e Extensão em } \\
\text { Sexualidade e Corporalidades }\end{array}$ & - \\
\hline Total & $\mathbf{0 4}$ & & - \\
\hline
\end{tabular}

Fonte: UFRPE 2014.

Nos Quadros 3 e 4 apresentamos a localização dos núcleos de estudos e pesquisas que discutem diretamente a mulher e as relações de gênero nas regiões Norte e Nordeste, os quais foram coletados nos anais do $18^{\circ}$ Encontro da REDOR, realizado pela Universidade Federal Rural de Pernambuco, em novembro de 2014. 
No Nordeste, em 1981, foi fundado o primeiro Núcleo de Estudos e Pesquisa na UFBA, em Salvador, o NEIM. Uma década depois, cinco núcleos já haviam sido criados e os demais nos anos seguintes, além da criação da REDOR, em 1992. No decorrer de quase quatro décadas de pesquisa, os núcleos vinculados à REDOR, 18 na região Nordeste e 04 na região Norte, estão a desenvolver estudos e pesquisas em 16 instituições de ensino superior e institutos de pesquisa. Foi possível identificar, parcialmente, o número de 246 pesquisadores/as vinculados/as a 14 núcleos do Nordeste a partir das informações contidas no site da REDOR. Isso pode fragilizar nossos argumentos, pelo fato de que quatro núcleos do Nordeste e quatro no Norte não disponibilizaram todas as informações sobre seus/suas pesquisadores/as e sobre as pesquisas em desenvolvimento.

Cabe questionar, após esta rápida contextualização, porque os estudos de gênero ainda não avançaram na pós-graduação em educação, com a mesma intensidade da disseminação dos núcleos no Nordeste, visto que no Norte nem todos os estados possuem núcleos que desenvolvem pesquisas sobre as relações de gênero. Ainda seria preciso o desenvolvimento de novas pesquisas para encontrar os resultados mais próximos da realidade, mas, é possível discutir alguns indicadores que desfavorecem o desenvolvimento das pesquisas de gênero na pósgraduação em educação. O primeiro seria o fato de que a formação dos/as pesquisadores/as dos núcleos, em sua grande maioria, é multidisciplinar (Educação, Sociologia, Antropologia, Historia, Saúde, Direito, Letras, etc.); isso faz com que esses/as pesquisadores/as se vinculem a programas de pós-graduação em várias áreas do conhecimento para desenvolverem suas atividades de ensino e pesquisas. O segundo está relacionado ao próprio processo lento de desenvolvimento da pósgraduação nessas regiões, como exposto nos Quadros 1 e 2. Alguns programas de pós-graduação do Norte e Nordeste ainda não passaram pela primeira avaliação da comissão de área da CAPES, dificultando a inserção de pesquisadores/as que desenvolvem pesquisas de gênero e, consequentemente, a formação de novos/as pesquisadores/as. O terceiro está relacionado às políticas públicas de apoio aos núcleos, na medida em que algumas universidades não colaboram amplamente com a manutenção dos núcleos, deixando a cargo do/a pesquisador/a a obrigação de arrecadar recursos através de editais de financiamento. 
No que se refere às pesquisas desenvolvidas sobre gênero no campo da educação, realizamos uma busca no banco de dados do Diretório de Grupos de Pesquisa no Brasil (CNPq) e constatamos a existência de mais de 50 grupos de pesquisas vinculados às instituições e aos programas de pós-graduação em educação do Norte e Nordeste, mas apenas 28 estão ligados à REDOR. Esses/as pesquisadores/as estão desenvolvendo pesquisas e orientações nas temáticas de gênero, corpo e sexualidades da graduação a pós-graduação, o que contribui para a disseminação e a produção do conhecimento na área, na medida em que a política de desenvolvimento da pós-graduação em educação avança nessas regiões.

Outro aspecto relevante é a pesquisa em educação, pois, se há um número grande de pesquisadores/as desenvolvendo estudos na área da diversidade de gênero e sexual, o método e os procedimentos devem ser pautados na perspectiva qualitativa e cultural. A pesquisa qualitativa está mais próxima das perspectivas de análise dos estudos culturais - as imagens de gênero se constituem como uma de suas vertentes analíticas -, que mostram como as identidades masculinas e femininas são construídas nas relações sociais. Parte-se da premissa de que os estudos de gênero inserem-se no campo do multiculturalismo, tendo como pauta principal de discussão, a ambiguidade da identidade/diferença (DIAS, 2014a). Entende-se que o reconhecimento da diferença e a realização da igualdade é que estão no centro das lutas emancipatórias de movimentos e grupos sociais que reivindicam um novo ideal de cidadania e a construção de um multiculturalismo emancipatório. Assim, a metodologia de compreensão aplicada nos estudos culturais chama a atenção para os impactos das relações sociais de gênero, que se articulam entre a cultura e o contexto social contemporâneo (MATTELART, 2004; HALL, 2003).

A cultura é um conjunto de significados/significantes que, através das tradições, se desvia para uma nova forma de situar-se, produzir-se, no sentido mais amplo, num processo de metamorfose em que conceitos, compreensões e caminhos mais modernos permitem o surgimento de novos sujeitos. Nessa linha de pensamento, Denzin aborda novas formas de inserir no campo da pesquisa qualitativa desdobramentos relacionados às perspectivas interpretativas específicas: "[...] feminismos, discursos racializados, estudos culturais, sexualidade e teoria queer". (DENZIN, 2006, p. 11) 
Algumas pesquisas podem ser citadas neste texto como demonstrativo da importância da análise de gênero na pós-graduação. Entre os anos 2010-2012, Maria Helena Santana Cruz, professora permanente do Programa de Pós-graduação em Educação e pesquisadora do Núcleo de Estudos Interdisciplinares sobre a Mulher e Relações de Gênero - NEPIMG, vinculados a Universidade Federal de Sergipe, publicou o livro Mapeando Diferenças de Gênero no Ensino Superior da Universidade Federal de Sergipe (2012), no qual apresenta dados empíricos de três grandes pesquisas financiadas pelo CNPq, pela CAPES e Secretaria de Políticas para as Mulheres (SPM). A autora discutiu os resultados nas seguintes abordagens: a) diferenças de gênero e classe no trabalho docente na Universidade Federal de Sergipe; b) memórias e experiências de docentes aposentados/as da Universidade Federal de Sergipe; c) diferenças de gênero e classe em egressos de escolas públicas na Universidade Federal de Sergipe.

Maria Eulina Pessoa de Carvalho, do Programa de Pós-graduação em Educação da Universidade da Paraíba, publicou, em 2013, o livro Gênero e Educação Superior: apontamentos sobre o tema, no qual apresenta uma discussão da perspectiva de gênero nas carreiras universitárias em 50 anos na UFPB, as Legislações e políticas de equidade de gênero no campo da educação no Brasil e na Paraíba. Também é necessário analisar como essas temáticas estão sendo inseridas e desenvolvidas nas escolas (DIAS, 2014b) para que possamos desconstruir a produção de corpos generificados, na tentativa de problematizar a reprodução das diferenças (DIAS, 2013).

As diversidades e desigualdades estão configuradas a partir das especificidades das Regiões Norte e Nordeste, mas acreditamos que é preciso ampliar as perspectivas teóricas e metodológicas na formação dos pesquisadores na perspectiva da alteridade.

\section{A FORMAÇÃO DO PESQUISADOR EM EDUCAÇÃO PARA A DIVERSIDADE}

Observa-se que o espaço de formação de pesquisadores tem-se desenvolvido de forma paulatina. Nesse cenário, faz-se necessário pensarmos a formação do pesquisador a partir da inclusão do princípio da diversidade e da alteridade, na tentativa de contribuir para a promoção da equidade nas relações 
interpessoais, diminuindo as desigualdades existentes na pós-graduação em educação, nas universidades e na educação básica.

Através de uma busca no banco de teses da Capes sobre tópicos relacionados a gênero e docência, foi possível organizar as pesquisas nos seguintes aspectos: divisão sexual do trabalho; relações de gênero no ensino fundamental; feminização do magistério; o masculino nas ciências exatas e o feminino nas ciências humanas; sexualidade na escola. $O$ desenvolvimento dessas pesquisas e seus principais resultados são importantes para o nosso debate. Apesar da diversidade de temáticas expostos neste levantamento exploratório realizado, há uma necessidade de analisar a introdução das abordagens sobre corpo, gênero, sexualidades e diversidade cultural na formação do professor e do pesquisador em educação, a fim de trazer para o debate acadêmico novas perspectivas teóricopráticas de análise.

A partir da análise das pesquisas brasileiras, especialmente no Norte e Nordeste, foi possível perceber um processo de construção de novas identificações dos pesquisadores e profissionais da educação, bem como constatar um número expressivo de textos que abordam as relações de gênero no campo da educação. Verificamos também a necessidade de intensificar a análise das relações de gênero no trabalho docente superior, especialmente pelo fato de que nessa etapa é que se desenvolve a formação inicial do professor, continuando na pós-graduação.

Particularmente em Sergipe, a formação do pesquisador em educação é ofertada pela Universidade Federal de Sergipe e pela Universidade Tiradentes. Contudo, para este texto vamos discutir a produção do conhecimento na temática de gênero e na formação de novos pesquisadores durante seus 20 anos de atuação. Abaixo, segue um resumo das dissertações e teses encontradas na Biblioteca do Programa de Pós-graduação em Educação - PPGED da Universidade Federal de Sergipe.

Quadro 5: Dissertações defendidas entre 2005-2014 no PPGED

\begin{tabular}{|c|l|c|}
\hline \multicolumn{1}{|c|}{ AUTOR } & \multicolumn{1}{|c|}{ TITULO } & ANO \\
\hline Lucyana Sobral de Souza & $\begin{array}{l}\text { Abordagem de gênero sobre a experiência de alunos } \\
\text { integrantes do Projovem Urbano na cidade de Aracaju - } \\
\text { Sergipe. }\end{array}$ & 2014 \\
\hline Anabela Maurício de Santana & $\begin{array}{l}\text { Relações de gênero, trabalho e formação docente: } \\
\text { experiência de mulheres da Escola Estadual Prof. Valnir } \\
\text { Chagas em Aracaju/SE }\end{array}$ & 2014 \\
\hline
\end{tabular}




\begin{tabular}{|l|l|c|}
\hline Susana Rezende Lima & $\begin{array}{l}\text { Representações de gênero sobre o trabalho, a } \\
\text { qualificação e as novas competências no COE - } \\
\text { Comando de Operações Especiais da PM/SE. }\end{array}$ & 2013 \\
\hline $\begin{array}{l}\text { Luciano Rodrigues dos } \\
\text { Santos }\end{array}$ & $\begin{array}{l}\text { Educação, Saúde e Sexualidade: revelações da inserção } \\
\text { do projeto saúde e prevenção nas escolas em Aracaju }\end{array}$ & 2011 \\
\hline $\begin{array}{l}\text { Maria Santana Ferreira dos } \\
\text { Santos Milhomem }\end{array}$ & $\begin{array}{l}\text { As representações de gênero na formação de } \\
\text { professores indígenas Xerente e expressão da violência. }\end{array}$ & 2010 \\
\hline Luiz Carlos Santos Prado & $\begin{array}{l}\text { Tempos de casas e labirintos: o lugar da avó na } \\
\text { trajetória feminina de Lya Luft }\end{array}$ & 2010 \\
\hline $\begin{array}{l}\text { Mariana Dórea Figueiredo } \\
\text { Pinto }\end{array}$ & $\begin{array}{l}\text { Abordagem de Gênero no Trabalho no Campo da } \\
\text { Contabilidade no Estado de Sergipe }\end{array}$ & 2009 \\
\hline $\begin{array}{l}\text { Maria Aparecida Souza } \\
\text { Couto }\end{array}$ & $\begin{array}{l}\text { Violências e gênero no cotidiano escolar: estudo de caso } \\
\text { em uma escola da rede pública estadual sergipana }\end{array}$ & 2008 \\
\hline Carla Rezende Gomes & $\begin{array}{l}\text { A prática pedagógica e a construção das identidades de } \\
\text { gênero em escola da rede municipal de ensino de } \\
\text { Aracaju/SE }\end{array}$ & 2008 \\
\hline $\begin{array}{l}\text { Patrícia Rosalba Salvador } \\
\text { Moura Costa }\end{array}$ & $\begin{array}{l}\text { Entre o Fato e a Lei: Representação, Justiça e Gênero - } \\
\text { Estupro em Aracaju }\end{array}$ & 2006 \\
\hline Fernanda Oliveira de Araújo & $\begin{array}{l}\text { Gênero na construção civil: um estudo de caso sobre as } \\
\text { trabalhadoras da Norcon. }\end{array}$ & 2005 \\
\hline
\end{tabular}

Fonte: Acervo da Biblioteca do PPGED, 2014.

Quadro 6: Teses defendidas entre 2012-2014 no PPGED

\begin{tabular}{|l|l|c|}
\hline \multicolumn{1}{|c|}{ AUTOR } & \multicolumn{1}{|c|}{ TíTULO } & ANO \\
\hline $\begin{array}{l}\text { Suzana Mary de Andrade } \\
\text { Nunes }\end{array}$ & $\begin{array}{l}\text { Uma leitura de histórias de vida de mulheres docentes } \\
\text { da Universidade Federal de Sergipe e da Universidade } \\
\text { do Porto }\end{array}$ & 2014 \\
\hline Maria Aparecida Souza Couto & $\begin{array}{l}\text { Representações de masculinidades e identidades de } \\
\text { gênero de estudantes do Ensino Médio e a relação com } \\
\text { as violências na Escola Pública }\end{array}$ & 2013 \\
\hline Elza Ferreira Santos & $\begin{array}{l}\text { Gênero, Educação Profissional e Subjetivação: } \\
\text { discursos e sentidos no cotidiano do Instituto Federal de } \\
\text { Sergipe }\end{array}$ & 2013 \\
\hline $\begin{array}{l}\text { Silmere Alves Santos de } \\
\text { Souza }\end{array}$ & $\begin{array}{l}\text { Trabalho docente, família e vida pessoal - } \\
\text { permanências, deslocamentos e mudanças } \\
\text { contemporâneas }\end{array}$ & 2012 \\
\hline
\end{tabular}

Fonte: Acervo da Biblioteca do PPGED, 2014.

Conforme levantamento feito, nos últimos nove anos poucas pesquisas de mestrado e doutorado investigaram a temática da diversidade de gênero e sexual no campo da educação. Isso pode ser um reflexo da pouca evidência dessas temáticas na formação do pesquisador em educação e, principalmente, na produção do conhecimento sergipano, visto que apenas 11 mestres e 04 doutoras em educação realizaram pesquisas sobre gênero e, especificamente seis dissertações e quatro teses analisaram o campo da educação na perspectiva de gênero.

\section{CONSIDERAÇÕES FINAIS}


É bastante perceptível a necessidade de ampliar as análises das representações sociais e de gênero nas relações do trabalho docente, compreendendo o meio acadêmico como um espaço interdisciplinar para a formação docente para a atuação em diversos espaços, principalmente na educação básica. Com isso, alguns argumentos podem ser usados para justificar a inclusão das temáticas de gênero, corpo e sexualidades na pós-graduação em educação. O primeiro é que as representações dos corpos masculinos e femininos são questionadas com base nas questões coexistentes nas práticas sociais que influenciaram e influenciam a forma pela qual, homens e mulheres desenvolvem, representam ou reproduzem uma Pedagogia do corpo. Historicamente as mulheres foram prejudicadas mediante o estabelecimento de papéis e lugares para homens e mulheres no processo de socialização (DIAS, 2013), influenciando diretamente sua atuação no campo da educação.

O segundo argumento é que no processo educativo as pessoas são ensinadas a controlar a sexualidade, o desejo, e a desenvolver papéis sociais ligados à masculinidade e à feminilidade; daí a tendência é que se reproduzam essas práticas simbólicas de controle quando os professores desenvolvem suas aulas considerando suas identificações sociais, em alguns casos, como se docentes e alunos não tivessem corpos, a fim de trabalhar apenas e puramente com a mente (HOOKS, 2010). O fato é que professores/as aprendem a silenciar o desejo no processo pedagógico e reproduzem esse comportamento constantemente em sala de aula, transformando as diferenças em desigualdades, a partir do investimento no distanciamento da mente e corpo. Isso ocorre no momento em que normatiza a formação de homens e mulheres, quando desenvolve uma linguagem que padroniza masculinidades e feminilidades, quando, nas situações diárias, despreza as experiências e inter-relações de alunos e alunas e professores e professoras.

Neste sentido, a incluir a perspectiva da diversidade na formação do professor/a pesquisador/a, estaremos contribuindo para a conscientização dos profissionais da educação e contribuindo com o papel da universidade no sentido de participar ativamente das relações sociais, na tentativa de diminuir as desigualdades. A formação dos professores e professoras e as práticas educativas estão mais sensíveis às questões de gênero, atualmente. Percebe-se a necessidade de refletir mais acerca da construção e desconstrução das representações dos 
significados das masculinidades e feminilidades no campo da educação, seja nas salas de aula como também nos cursos de formação de professores. (CARVALHO, 2009). Percebe-se que o caminho inicial para a democratização das práticas escolares está intimamente ligado ao processo educativo. Neste sentido, "admite-se que a educação, os processos escolares e as ações docentes influenciam a equidade ou iniquidade de gênero e, inversamente, que o gênero impacta as experiências e os resultados educacionais" (CARVALHO, 2012, p. 31).

O desenvolvimento da pós-graduação no Norte e Nordeste está dando abertura para a inserção de pesquisadores/as de gênero, mas a formação do/a pesquisador/a ainda é desigual nessas regiões haja vista que um estado do Nordeste (Maranhão) e quatro do Norte ainda não possuem nível de doutorado, o que fragiliza a formação nessas regiões. Assim, espera-se que este estudo contribua para despertar em nós, pesquisadores/as dessas regiões, a vontade de olhar para "nós mesmos", discutir sobre nossas ações, nos projetos profissionais e, principalmente, nossa atuação política dentro dos espaços públicos.

Espera-se que este texto impacte ou de alguma forma dê visibilidade às contribuições dos/as pesquisadores/as do Norte e Nordeste que desenvolvem pesquisas e conhecimento acadêmico sobre gênero, visto que ao mapear o desenvolvimento, a diversidade e as desigualdades na pós-graduação em educação e a constituição dos núcleos de estudos e pesquisas integrantes da REDOR foi possível identificar que a atuação de muitos/as pesquisadores/as sobre gênero está interligada.

Faz-se necessário salientar que a falta de apoio institucional e o preconceito sofridos por muitos/as pesquisadores/as, pelo fato de pesquisarem gênero na academia ainda impõem barreiras para o aumento da visibilidade aos estudos de gênero. Apesar desses aspectos desfavoráveis os/as pesquisadores/as, ao se inserirem nos programas de pós-graduação, desenvolvem uma postura militante para a sustentação dos núcleos e grupos de pesquisas, para a produção e disseminação do conhecimento, bem como para o fortalecimento da formação de novos/as pesquisadores/as em nível de doutorado para impactar também na educação básica.

Nessa perspectiva, ao ampliar a análise sobre gênero no campo da educação, poderemos contribuir para a construção de uma política de educação não 
discriminadora (DIAS, 2014d) que questione estereótipos, preconceitos, normatizações, desigualdades de gênero, sexual, étnicas, raciais, geração, classe.

Esse processo acontece por meio da formação de professores e professoras, conforme a literatura específica sobre estudos de gênero tem mostrado. As condições em que a inclusão das temáticas influencia a formação docente são: a) as temáticas do corpo, gênero e sexualidades aparecem de modo imprevisto na sala de aula (SEFFNER, 2011; DORNELLES; POCAHY, 2014; PINTO, 2011); b) a escola é uma instituição na qual se disputam, se aceitam, se rejeitam e se impõem significados através de processos em que os agentes se encontram inseridas, participando de negociações culturais ou imposições muito complexas (WENETZ, 2012; DORNELLES, 2012); c) a potencialidade destas novas vozes mostra que as discriminações dos papéis relacionados ao gênero na educação são provocadas por forças sociais, mas que pode haver uma resistência a estas determinações, resistência demarcada no sucesso da entrada de transexuais e travestis na docência (RABELO, 2013; TORRES; PRADO, 2014); d) aspectos ligados às temáticas do corpo, gênero e sexualidades são considerados no planejamento das aulas de parte dos/as docentes, repercutindo na formação de uma existência habitável no espaço escolar que se constitui como uma direção potente para a fuga dos caminhos de articulação entre marcadores (ALTMAN; AYOUB; AMARAL, 2011; MOIZÉS; BUENO; 2010); e) o reconhecimento, por parte dos/as professores/as, de suas limitações conceituais e a disponibilidade para a capacitação, o que demonstra a sensibilidade para problematizar a discussão sobre sexualidade no espaço escolar, concordando que o tema tem relevância social para ser implementado (QUIRINO; ROCHA, 2012; EHRENBERG, 2014); f) os agentes escolares se mostram abertos à construção de novas formas de dar sentido às questões do corpo, gênero, sexualidades e às múltiplas possibilidades de constituição de masculinidades e feminilidades, desde que instigadas a pensar e a demonstrar estranhamento sobre 0 que é proposto como natural (XAVIER FILHA, 2012; SILVA; SOARES, 2014; ALONSO; ZURBRIGGEN, 2014).

Uma característica é comum entre os estudos analisados relativos às temáticas sobre corpo, gênero, sexualidades e formação docente: o fato de que todos sugerem que a abordagem das temáticas contribui para a desestabilização de normatizações, classificações e hierarquizações no campo da educação. 
Espera-se que ao dar visibilidade aos estudos da diversidade e desigualdade de gênero na Pós-Graduação em Educação do Norte e Nordeste possamos desenvolver o pensamento crítico-reflexivo no que concerne à educação não discriminadora, suas interfaces e perspectivas teórico-metodológicas. Que os/as pesquisadores/as possam articular seus conhecimentos de forma interdisciplinar, envolvendo conhecimentos educacionais, acerca da diversidade de gênero, na busca pela produção de novas saberes educacionais. Enfim, que ressignifiquem suas concepções acerca da educação básica, a partir do convívio cotidiano com sua realidade, compreendendo esta realidade como dinâmica e suscetíveis às ações do Estado e dos profissionais que nela atuam, a fim de que possam ampliar suas argumentações sobre a diversidade de gênero.

\section{ALFRANCIO FERREIRA DIAS}

Doutor em Sociologia pela Universidade Federal de Sergipe (UFS). Professor do Programa de Pós-Graduação em Educação e do Departamento de Educação da Universidade Federal da Sergipe. Pesquisador do Núcleo de Estudos e Pesquisas Interdisciplinares sobre a Mulher e Relações Sociais de Gênero (NEPIMG/UFS).

\section{REFERÊNCIAS}

ALONSO, G. B.; ZURBRIGGEN, R.. Transformando corporalidades: Desbordes a la normalidad pedagógica. Educar em Revista, Curitiba, Edição Especial, n. 1, p. 5369, 2014.

ALTMAN, H.; AYOUB, E.; AMARAL, S.C.F. Gênero na prática docente em educação física: "meninas não gostam de suar, meninos são habilidosos ao jogar"? Revista Estudos Feministas, Florianópolis, v. 19, n. 2, p. 491-501, 2011.

BEAUVOIR, S. O segundo sexo: fatos e mitos.4.ed. São Paulo: Difusão Europeia do Livro, 1970, 309p.

BUTLER, J. Problemas de gênero: feminismo e subversão da identidade. 2.ed. Rio de Janeiro: Civilização Brasileira, 2010, 236p.

CANDAU, V. M.. Multiculturalismo e educação: desafios para a prática pedagógica. In: CANDAU, V. M.; MOREIRA, A. F.. Multiculturalismo: diferenças culturais e prática pedagógicas. 4. ed. Petrópolis: Vozes, 2010, 245p.

COORDENAÇÃO DE APERFEIÇOAMENTO DE PESSOAL DE NÍVEL SUPERIOR (CAPES). Cursos recomendados/reconhecidos. (atualizado em 20 de maio de 2014). Disponível em: <http://www.capes.gov.br/cursos-recomendados>. Acesso em: 28 abr. 2015. 
CARVALHO, M. P. Diferenças e desigualdades na escola. Campinas (SP): Papirus, 2012, 192p.

CARVALHO, M. E. P.; RABAY, G.I. Gênero e educação superior: apontamentos sobre o tema. João Pessoa: EDUFPB, 2013, 84p.

CARVALHO, M. E. P. Inclusão da perspectiva de gênero na educação e na formação docente. In: TEIXEIRA, A.B.M.; DUMONT, A. (orgs). Discutindo relações de gênero na escola: reflexões e propostas para a ação docente. Araraquara (SP): Junqueira \& Marin; Belo Horizonte/MG: GSS; FUNDEP, 2009, p.24-43.

CRUZ,M. H. S.; FRANÇA, V. L. A. Educação feminina: memória e trajetórias de alunas do Colégio Sagrado Coração de Jesus em Estância(SE). São Cristóvão: Editora UFS, 2011, 193p.

CRUZ, M. H. S.. Mapeando diferenças de gênero no ensino superior da universidade Federal de Sergipe. São Cristóvão: EDUFS, 2012, 368p.

DENZIN, N. K. O planejamento da pesquisa qualitativa: teorias e abordagens. Porto Alegre: Artmed, 2006, 423p.

DIAS, A.F. Educando corpos, produzindo diferenças: um debate sobre gênero nas práticas pedagógicas. Revista TOMO, n. 23, p. 237-257, jul/dez 2013.

DIAS, A. F. Representações sociais de gênero no trabalho docente: sentidos e significados atribuídos ao trabalho e a qualificação. Vitória da Conquista: Edições UESB, 2014a, 267p.

DIAS, A. F. Como as escolas educam corpos nas práticas pedagógicas. Revista Tempos e Espaços em Educação, v. 07, n. 12, p. 103-112, 2014b.

DIAS A. F. Formação de professores para uma educação não discriminadora. Aracaju, Infografhics, 2014d, 54p.

DORNELLES, P. G. Do corpo que distingue meninos e meninas na educação física escolar. Cadernos Cedes, Campinas, v. 32, n. 87, p. 187-197, 2012.

DORNELLES, P. G.; POCAHY,F. A. "Prendam suas bezerras que o meu garrote está solto!" Interseccionando gênero, sexualidade e lugar nos modos de subjetivação regionais. Educar em Revista, Curitiba, Edição Especial n. 1, p. 117133, 2014.

DUBAR, C. A socialização: construção das identidades sociais e profissionais. São Paulo: Martins Fontes, 2005, 305p.

EHRENBERG, M. C. A linguagem da cultura corporal sob o olhar de professores da educação infantil. Pro-Posições, v. 25, n. 1 (73), p. 181-198, 2014. 
HALL, S. Da diáspora: identidades e mediações culturais. Belo Horizonte: UFMG, 2003, 425p.

HOOKS, B. Eros, erotismo e o processo pedagógico. In: LOURO, G. O corpo educado: pedagogias da sexualidade (org.). 3. ed. Belo Horizonte: Autêntica, 2010, p.67-73.

LAURETIS, T. A tecnologia de gênero. In: HOLANDA, H. B. (Org.). Tendências e impasses: o feminismo como crítica cultural. Rio de Janeiro: Rocco, 1994. p.206242.

LOURO, G. L. Gênero, sexualidade e educação: uma perspectiva pós-estruturalista. 11. ed. Petrópolis: Vozes, 2010, 282p.

MATTELART, A. Introdução aos estudos culturais. São Paulo: Parábola Editorial, 2004, 243p.

MERCADO, L. P. L.; CAVALCANTE, M. A. S. Formação do Pesquisador em Educação: profissionalização docente, políticas públicas, trabalho e pesquisa. Maceió: EDUFAL, 2007, 353p.

MILLETT, K. Política sexual. Lisboa: Companhia Dom Quixote, 1970, 211p.

MOIZÉS, J. S.; BUENO, S. M. V. Understanding sexuality and sex in schools according to primary education teachers. Revista da Escola de Enfermagem da USP, v. 44 , n. 1 , p. $200-207,2010$.

PINTO, J. P. Ler e escrever sobre corpos: metodologia feminista para letramento de jovens. Cadernos de Pesquisa, v. 41, n. 143, p. 538-558, 2011.

QUIRINO, G. S.; ROCHA, J. B. T. Sexualidade e educação sexual na percepção docente. Educar em Revista, Curitiba, Brasil, n. 43, p. 205-224, 2012.

RABELO, A. Debates sobre gênero na docência: o professor do sexo masculino nas séries iniciais do Rio de Janeiro-Brasil e Aveiro-Portugal. Educar em Revista, Curitiba, v. 34, n. 48, p. 207-234, 2013

ROSEMBERG, F.; PINTO, R. P. A educação da mulher. São Paulo: Nobel (Conselho Municipal da Condição Feminina), 1985, 219p.

SCOTT, J.. Gênero: uma categoria útil de análise histórica. Educação e Realidade, v. 20, n. 2, p. 71-99, jul/dez 1995.

SEFFNER, F.. Um bocado de sexo, pouco giz, quase nada de apagador e muitas provas: cenas escolares envolvendo questões de gênero e sexualidade. Revista Estudos Feministas, Florianópolis, v. 19, n. 2, p. 561-572, 2011.

SILVA, T. T.. Documento de identidade: uma introdução às teorias do currículo. Belo Horizonte: Autêntica, 2010, 154p. 
SILVA,R. A.; SOARES, R.. Sexualidade e identidade no espaço escolar: notas de uma atividade em um curso de educação a distância. Educar em Revista, Curitiba, Edição Especial n. 1, p. 135-151, 2014.

TEIXEIRA, A. B. M.. (org.). Discutindo relações de gênero na escola: reflexões e propostas para a ação docente. Araraquara/SP: Junqueira \& Martin; Belo Horizonte/MG: FUNDEP, 2009, 189p.

THOMPSON, E. P. A miséria da teoria ou um planetário de erros. Rio de Janeiro: Zahar, 1981, 223p.

TORRES; M. A.; PRADO, M. A. Professoras transexuais travestis no contexto escolar: entre estabelecidos e outsiders. Educação \& Realidade, Porto Alegre, v. 39, n. 1, p. 201-220, 2014.

UNIVERSIDADE FEDERAL RURAL DE PERNAMBUCO (UFRPE) 18을 REDOR. 24 a 27 de novembro de 2014. Anais Eletrônicos. Disponível em:

<http://www.ufpb.br/evento/ti/ocs/index.php/18redor/18redor>. Acesso em: 28 abr. 2015.

XAVIER FILHA, C. A menina e o menino que brincavam de ser...: representações de gênero e sexualidade em pesquisa com crianças. Revista Brasileira de Educação, v. 17, n. 51, p. 627-646, 2012.

WALSH, C. La educación intercultural em la educación. Peru: Ministerio de Educación, 2001, 154p.

WENETZ, I. Gênero, corpo e sexualidade: negociações nas brincadeiras do pátio escolar. Cadernos Cedes, Campinas, v. 32, n. 87, p. 199-209, 2012. 